4 Muir A, Palmer RL. An audit of a British sample of death certificates in which anorexia nervosa is listed as a cause of death. Int J Eat Disord 2004; 36: 356-60.

5 Royal College of Psychiatrists, Royal College of Physicians. MARSIPAN: Management of Really Sick Patients with Anorexia Nervosa (College Report CR162). Royal College of Psychiatrists, 2010.

6 Sikora K. Catena Di Mauro - the tragic face of anorexia. New South Wales Daily Telegraph 2009, 11 February.

7 BBC News. Care changes after anorexia death. 6 October 2009 (http:// news.bbc.co.uk/1/hi/england/norfolk/8293441.stm).

8 Aubert F. Les médecins ont tué ma fille en l'endormant. [The doctors killed my daughter by sending her to sleep.] 20 Minutes Online, 17 January 2011 (http://www.20min.ch/ro/entertainment/people/story/ 21742693)

9 Scottish Parliament. Case 200400447: Lothian NHS Board. Scottish Parliament, 2006 (http://www.spso.org.uk/webfm_send/114).

10 National Institute for Health and Clinical Excellence. Nutrition Support in Adults (Clinical Guidelines CG32). NICE, 2006.

11 Mehler PS, Winkelman AB, Andersen DM, Gaudiani JL. Nutritional rehabilitation: practical guidelines for refeeding the anorectic patient. J Nutr Metab 2010; doi: 10.1155/2010/625782.

12 National Institute for Health and Clinical Excellence. Eating Disorders: Core Interventions in the Treatment and Management of Anorexia Nervosa,
Bulimia Nervosa and Related Eating Disorders (Clinical Guideline CG9). NICE, 2004

13 Junior MARSIPAN Group. Junior MARSIPAN: Management of Really Sick Patients under 18 with Anorexia Nervosa (College Report CR168). Royal College of Psychiatrists, 2011.

14 Emborg C. Mortality and cause of death in eating disorders in Denmark 1970-1993: a case register study. Int J Eat Disord 1999; 25: 243-51.

15 Button EJ, Chadalavada B, Palmer RL. Mortality and predictors of death in a cohort of patients presenting to an eating disorders service. Int J Eat Disord 2010; 43: 387-92.

16 Cohen SI. Hostile interaction in a general hospital ward leading to disturbed behaviour and bulimia in anorexia nervosa: its successful management. Postgrad Med J 1978; 54: 361-3.

17 Fleming J, Szmukler GI. Attitudes of medical professionals towards patients with eating disorders. Aust N Z J Psychiatry 1992; 26: 436-43.

18 King SJ, de Sales T. Caring for adolescent females with anorexia nervosa: registered nurses' perspective. J Adv Nurs 2000; 32: 139-47.

19 George L. The psychological characteristics of patients suffering from anorexia nervosa and the nurse's role in creating a therapeutic relationship. J Adv Nurs 1997; 26: 899-908.

20 Intercollegiate Group on Nuntrition. Undergraduate Nutrition Educational Curriculum Overview. ICGN, 2010 (http://www.icgnutrition.org.uk/ forum/messages/725/725.html).

\title{
Assessing fitness to drive in dementia and other psychiatric conditions: a higher training learning opportunity at a driving assessment centre
}

\author{
Matthew P. Sheridan ${ }^{1}$
}

The Psychiatrist (2012), 36, 113-116, doi: 10.1192/pb.bp.111.034983

${ }^{1}$ Elderly Mental Health Services, North West Kilmarnock Area Centre, NHS Ayrshire \& Arran, UK

Correspondence to Matthew Sheridan (m.sheridan@doctors.org.uk)

First received 18 Apr 2011, final revision 31 Aug 2011, accepted 26 Sep 2011

\begin{abstract}
Summary With an ageing population and expected rise in cases of dementia, driving safety will become increasingly important. Doctors have a professional obligation to identify patients who are unsafe to drive and in cases of dementia this decision is often complex. As a result, many centres in the UK offer driving assessments for people with medical conditions that may affect their on-road performance. I aim to identify a valuable learning opportunity for psychiatrists in training, particularly those working with older adults, to improve their knowledge of driving assessment. I also provide an overview of the Scottish Driving Assessment Service and reflect on my visit there.
\end{abstract}

Declaration of interest None.
Much emphasis has been placed within medical practice on professionals' obligation to have a good working knowledge of driving guidance. In psychiatry this is reflected in the higher training curriculum ${ }^{1}$ and within old age psychiatry clinicians are frequently challenged with the assessment of driving safety in individuals with dementia. In the face of an increasingly older population, driving safety will become even more important. By 2021, the number of people with dementia in the UK is expected to rise from 750000 to over 1 million, rising to 1.7 million by $2051 .{ }^{2}$ The number of older people holding driving licences is also increasing. The percentage of people aged over 70 who have a driving licence has increased from $27 \%$ in 1985 to $54 \%$ (76\% in males, $37 \%$ in females) in $2009^{3}$

\section{Dementia and driving safety assessments: research evidence}

Iverson and colleagues performed a systematic review of the evidence for predicting driving safety in dementia. ${ }^{4}$ They 
found that the severity of dementia is associated with increased driving risk, yet no specific cut-off point on the Mini-Mental State Examination (MMSE) or Clinical Dementia Rating offered a reliable predictor for failing an on-road driving test. Iverson et al commented that beyond defining dementia severity, 'there is insufficient evidence to support or refute the benefit of neuropsychological testing in evaluating driving risk in patients with dementia'.

Driving is a complex skill reliant on cognitive, visual and physical factors. A review by Anstey and colleagues explores these factors and, importantly, makes the connection between the skills and the person's ability to self-monitor and adjust driving behaviour accordingly. ${ }^{5}$ Within psychiatry, self-monitoring or insight is an integral part of the mental state and often varies depending on severity and type of disorder. For instance, a study examining patients' beliefs about their driving ability showed that $94 \%$ of people with mild Alzheimer's dementia believed they were safe drivers, but only $41 \%$ passed an on-road driving test. ${ }^{6}$ This compared with $100 \%$ of age-matched controls believing they were safe and $84 \%$ passing the test.

McKenna explored fitness to drive from a neuropsychological perspective and identified the key areas of cognition. Visuospatial analysis and shape perception are involved in accurate manoeuvring of the car in the environment; selective attention is essential for focusing and switching between multiple visual stimuli; and executive function is important in making sense of these stimuli and involves continual monitoring of a situation and adjusting behaviour accordingly. ${ }^{7}$

\section{Driving safety in other psychiatric conditions}

Assessing driving safety is not specific to old age psychiatry and other psychiatric conditions have also been investigated. Harris conducted an analysis of 250 police reports given to the Driver and Vehicle Licensing Agency (DVLA) in $1995 .{ }^{8}$ Where illness or disability (not including alcohol and substance intoxication) were implicated, psychiatric disorders made up the largest single cause of accidents. Among these, dementia accounted for $58 \%$, hypomania for $12 \%$, schizophrenia and other psychoses for $14 \%$ and suicide attempt for $8 \%$. The author commented: 'There must be control over impulse and risk-taking. Judgement should be mature and unimpaired, with the ability to anticipate the actions of other road users' (p. 263). ${ }^{8}$ It is perhaps not surprising that all mental disorders have the potential to impair driving safety.

\section{Guidance on driving safety assessments}

The DVLA offers guidance about many psychiatric conditions and the section regarding dementia acknowledges that, 'It is extremely difficult to assess driving ability in those with dementia. Those who have poor short-term memory, disorientation, lack of insight and judgement are almost certainly not fit to drive' (p. 35). ${ }^{9}$ Recent updated guidance now includes mild cognitive impairment and advises that the DVLA does not need to be notified of this diagnosis. Although it is the DVLA who makes the final decision regarding licence renewal, this is based on medical reports and it is a doctor's professional obligation to advise a patient to stop driving if it is felt they are unsafe to do so.

Dementia ranges in severity and depending on aetiology, differing cognitive domains are affected. It can be very difficult therefore for a clinician to interpret the guidance specifically to individual patients and perhaps not surprisingly it is recognised that healthcare professionals struggle with DVLA guidance. In a study commissioned by the UK Department for Transport, Hawley identified poor condition-specific knowledge among healthcare professionals. ${ }^{10}$ She also reported that many healthcare professionals believed better training and clearer guidance on giving advice about fitness to drive were required.

I believe that psychiatric higher training affords the opportunity to expand these training needs from theoretical knowledge of assessment and guidance to 'real life' experience. I spent a day with the Scottish Driving Assessment Service (SDAS) in Edinburgh and describe the experience in this paper.

\section{Scottish Driving Assessment Service}

The SDAS was established in 1983 and is a member of the UK Forum of Mobility Centres. It is one of 17 such centres across Great Britain and Northern Ireland and although based in Edinburgh, the service also carries out assessments at 6 other hospital sites around Scotland using a mobile unit. The Service is funded jointly by the National Health Service and Transport Scotland, the transport agency of the Scottish Government, and accepts referrals from general practitioners (GPs), hospital specialists and directly from the Drivers Medical Group of the DVLA.

During 2009/2010, SDAS received a total of 1285 referrals and carried out 671 driving assessments. It has been running at capacity for some time and this is reflected in the waiting times, which show that demand for the service far outweighs the resources available (average waiting time ranges from 19 to 34 weeks depending on site). A breakdown of the figures for 2009/2010 reveals that just under a half of referrals are by hospital specialists (47\%), those from GPs account for $40 \%$ and direct requests from the DVLA account for $13 \%$. The majority of individuals undergoing assessment are aged between 46 and 85, with $42 \%$ of all individuals older than 66 . The breakdown of primary diagnoses demonstrates that dementia is the second most common diagnosis seen (Table 1).

The overall proportion of people advised not to drive following the assessment in 2009/2010 was $16.8 \%$. This compared with $46 \%$ in individuals with dementia as primary diagnosis (Table 2).

\section{The assessment process}

The assessment (Box 1) is performed by a therapist (occupational or physiotherapist) and also, in some cases, a specialist doctor in rehabilitation medicine. The person has a sight check to ensure legal requirements to drive are met. Following this, a full clinical history is taken as well as specific driving history, including: time since last drove, number of years of driving experience, recent accidents, current driving pattern and family's views of the person's driving ability. All individuals have visual fields, acuity and 


\begin{tabular}{ll}
$\begin{array}{l}\text { Table } 1 \\
\begin{array}{l}\text { Primary diagnoses of individuals assessed } \\
\text { by the Scottish Driving Assessment Service }\end{array}\end{array}$ & Assessments $(n)$ \\
\hline Diagnosis & 187 \\
\hline Stroke/cerebrovascular disease & 100 \\
\hline Dementia & 41 \\
\hline Multiple sclerosis & 37 \\
\hline Traumatic head injury & 31 \\
\hline Amputation & 29 \\
\hline Spinal cord damage & 26 \\
\hline Peripheral nerve injury & 23 \\
\hline Frail elderly & 21 \\
\hline Parkinson's disease & 18 \\
\hline Cerebral palsy & 14 \\
\hline Arthritis & 14 \\
\hline Psychiatric disorder & 62 \\
\hline Other neurological & 68
\end{tabular}

examination of ocular movements checked. If physical disability is present, a focused examination is performed. Higher cognitive function is examined using a number of assessments including MMSE, ${ }^{11}$ block design, ${ }^{12}$ trail making $\mathrm{B}^{12}$ and road signs. This is followed by a static assessment unit testing reaction times by assessing braking in response to randomly lit lights as well as checking accelerator control and braking force. The rig can also be used to test any modifications which may need to be made to the car in cases of physical disability.

The majority of individuals proceed to an on-road assessment, which is not a driving test but rather a test of safe driving ability. This commences in the hospital grounds in a dual-controlled car to allow the person to familiarise him- or herself with the vehicle, and proceeds to public roads. In Edinburgh a 14-mile route is taken, which includes major and side roads as well as dual carriageways, roundabouts and junctions. The individual is assessed on technical ability as well as factors such as attention, lane discipline and anticipatory planning. The staff member accompanying the person is usually one of the therapists and in the case of one of the experienced occupational therapists, a previously qualified driving instructor. At the end of the assessment, an

\section{Box 1 Assessment summary}

- Assessment of vision

- Driving history (previous and current driving pattern, relatives' views)

- Specific physical examination if disability present

- Higher cognitive functioning: Mini-Mental State Examination, block design (visuospatial skills), trail making B (attention and executive function)

- Reaction time test

- On-road assessment

overall judgement is made based on the whole performance, with weight being given to the on-road test. The individual is given immediate advice to either continue or stop driving immediately and a detailed assessment is written to the referring doctor. The driving service does not inform the DVLA of the assessment unless the DVLA was the referring body. It therefore remains the responsibility of the individual to do so.

\section{Shadowing driving assessments: reflections}

I spent a day with SDAS and observed three assessments. It was useful to learn the salient points of taking a focused driving history and to recap the DVLA guidelines. I would urge the reader to ensure they are familiar with the latest guidance on individual psychiatric diagnoses issued by the DVLA. ${ }^{9}$ When I joined the occupational therapist for an on-road assessment, I was surprised to notice that the person assessed showed poor safety awareness and made many errors of judgement that were not immediately obvious from the initial cognitive assessment and historytaking. The individuals seen during my visit lacked insight into how having dementia may affect their driving and were surprised and upset to hear that they were deemed unsafe to continue driving. I heard their own reasons for driving, including perceived reliance on it for independence. This highlighted the potential impact that being told to cease driving can have and reminded me of how potentially distressing it can be for people.

Following this experience, I felt more confident visualising how poor performance in certain cognitive tests may affect on-road capability and became more

Table 2 Outcome of assessments by the Scottish Driving Assessment Service in 2009-2010

$n(\%)$

\begin{tabular}{lccc} 
& & All drivers $(n=671)$ & Drivers diagnosed with dementia $(n=100)$ \\
\cline { 2 - 3 } Suitable & $299(44.6)$ & $39(39.0)$ \\
\hline Unsuitable & $113(16.8)$ & $46(46.0)$ \\
\hline May be suitable (learners) & $55(8.2)$ & $n / a$ \\
\hline For review & $139(20.7)$ & $1(1.0)$ \\
\hline
\end{tabular}

n/a, not applicable. 
certain when to advise a patient that they need to stop driving. The experience also highlighted the limitations of simple clinic cognitive tests such as the MMSE in predicting on-road safety and the difficulties clinicians face when making a decision. This echoes the DVLA guidance that recognises the challenges faced when assessing driving ability in dementia.

I have become more aware of the need to enquire about driving and remind patients with any significant cognitive deficit of their responsibility to inform the DVLA and the insurance company of their diagnosis. I have found that directing the patient to the Alzheimer's Society website (http://alzheimers.org.uk) can also be helpful and in addition I routinely write to the patient. The challenges of assessing whether a person is safe to drive will continue but I have become more focused on certain cognitive skills such as attention, visuospatial and executive functions, and tailor my history-taking and assessment accordingly. The value of an occupational therapist assessment should not be underestimated either, as problems in other activities of daily living should alert to the possibility of unsafe driving. I would usually refer a patient for a driving assessment if they are keen to continue driving but my assessment or the history has highlighted some areas of concern. If there are clear concerns, however, I advise the patient directly that they should stop driving and notify the DVLA. In the minority of cases, especially where insight may be low, the patient may choose to ignore the recommendation and continue to drive. In these circumstances there are clear guidelines issued by the General Medical Council on when to inform the DVLA without the patient's consent. ${ }^{13}$

In the face of an increasingly older population, driving safety is becoming even more important. Rising numbers of people with dementia and physical frailty will have obvious implications on the ability of driving assessment services across the UK to accommodate increasing requests from clinicians. The service offers an invaluable assessment, which is extremely difficult to recreate in everyday practice. In light of these pressures, I believe it is becoming ever more important for clinicians to have a sound knowledge and experience of this issue and I would urge all higher trainees to make use of their special interest sessions wisely and visit their local driving assessment centre.

\section{Acknowledgement}

I thank the staff at the Scottish Driving Assessment Service in Edinburgh, including Marlene McKenzie (manager) who helped to organise my visit and provided the data.

\section{About the author}

Matthew P. Sheridan is a Specialty Registrar 5 in old age psychiatry, currently working in North West Kilmarnock Area Centre, Kilmarnock, Scotland, UK.

\section{References}

1 Royal College of Psychiatrists. A Competency Based Curriculum for Specialist Training in Psychiatry: Specialists in Old Age Psychiatry. Royal College of Psychiatrists, 2010.

2 King's College London, London School of Economics and Political Science. The Rising Cost of Dementia in the UK. Alzheimer's Society, 2007.

3 Department for Transport. National Travel Survey 2009. Department for Transport, 2009

4 Iverson DJ, Gronseth GS, Reger MA, Classen S, Dubinsky RM, Rizzo M. Practice parameter update: evaluation and management of driving risk in dementia. Report of the Quality Standards Subcommittee of the American Academy of Neurology. Neurology 2010; 74: 1316-24.

5 Anstey KJ, Wood J, Lord S, Walker JG. Cognitive, sensory and physical factors enabling driving safety in older adults. Clin Psychol Rev 2005; 25: 45-65.

6 Brown LB, Ott BR, Papandonatos GD, Sui Y, Ready RE, Morris JC. Prediction of on-road driving performance in patients with early Alzheimer's disease. J Am Geriatr Soc 2005; 53: 94-8.

7 McKenna P. Fitness to drive: a neuropsychological perspective. J Ment Health 1998; 7: 9-18.

8 Harris M. Psychiatric conditions with relevance to fitness to drive. Adv Psychiatr Treat 2000; 6: 261-9.

9 Drivers Medical Group DVLA. For Medical Practitioners: At a Glance Guide to the Current Medical Standards of Fitness to Drive. DVLA, 2011.

10 Hawley C. Road Safety Research Report No. 91: The Attitudes of Health Professionals to Giving Advice on Fitness to Drive. Department for Transport, 2010.

11 Folstein MF, Folstein SE, McHugh PR. Mini-Mental State: a practical method for grading the cognitive state of patients for the clinician. J Psychiatr Res 1975; 12: 189-98.

12 Hodges JR. Cognitive Assessment for Clinicians, Second Edition. Oxford University Press, 2007.

13 General Medical Council. Confidentiality: Reporting Concerns about Patients to the DVLA or the DVA (Supplementary Guidance). GMC 2009 (http://www.gmc-uk.org/Confidentiality_reporting_concerns DVLA_2009.pdf_27494214.pdf). 